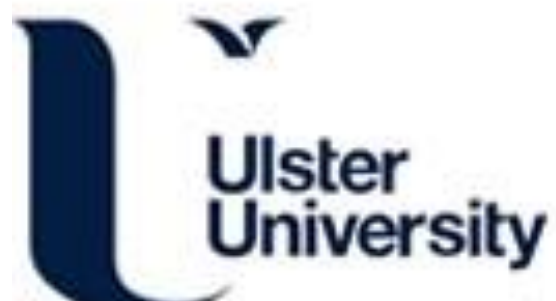

\section{A contemporary and systematic literature review of user centric innovation: A consumer perspective}

Gamble, J., Brennan, M., \& McAdam, R. (2019). A contemporary and systematic literature review of user centric innovation: A consumer perspective. In A. Brem (Ed.), Managing Innovation: Understanding and Motivating Crowds (1 ed., Vol. 1, pp. 1-55). [1] World Scientific Publishing. https://doi.org/10.1142/q0193

Link to publication record in Ulster University Research Portal

\section{Published in:}

Managing Innovation

Publication Status:

Published (in print/issue): 01/04/2019

DOI:

10.1142/q0193

\section{Document Version}

Author Accepted version

\section{General rights}

Copyright for the publications made accessible via Ulster University's Research Portal is retained by the author(s) and / or other copyright owners and it is a condition of accessing these publications that users recognise and abide by the legal requirements associated with these rights.

\section{Take down policy}

The Research Portal is Ulster University's institutional repository that provides access to Ulster's research outputs. Every effort has been made to ensure that content in the Research Portal does not infringe any person's rights, or applicable UK laws. If you discover content in the Research Portal that you believe breaches copyright or violates any law, please contact pure-support@ulster.ac.uk. 
See discussions, stats, and author profiles for this publication at: https://www.researchgate.net/publication/332018573

\section{A Contemporary and Systematic Literature Review of User-centric Innovation: A Consumer Perspective}

\section{Chapter · April 2019}

DOI: $10.1142 / 9781786346490 \_0001$

CITATIONS

3 authors:

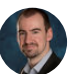

Jordan Gamble

Dublin City University

20 PUBLICATIONS 89 CITATIONS

SEE PROFILE

Rodney Mcadam

Ulster University

220 PUBLICATIONS 6,521 CITATIONS

SEE PROFILE

Some of the authors of this publication are also working on these related projects:

Project Agri-food innovation View project

Project Innovation and entrepreneurship in multi-generational family businesses View project
Michael Brennan

Ulster University

16 PUBLICATIONS 98 CITATIONS

SEE PROFILE 


\title{
A contemporary and systematic literature review of user-centric innovation: a
} consumer perspective

\author{
Jordan Robert Gamble ${ }^{a *}$ \\ jordan.gamble@dcu.ie
}

\author{
Michael Brennan ${ }^{\mathrm{b}}$ \\ m.brennan@ulster.ac.uk
}

Rodney McAdam ${ }^{\mathrm{b}}$

r.mcadam@ulster.ac.uk

\begin{abstract}
${ }^{a}$ DCU Business School, Dublin City University, Glasnevin Campus, Collins Avenue, Dublin 9, Ireland

${ }^{\mathrm{b}}$ Ulster University, Jordanstown campus, Shore Road, Newtownabbey, Co. Antrim, BT37 0QB

*corresponding author
\end{abstract}

\begin{abstract}
This paper provides a systematic literature review (SLR) of contemporary user-centric innovation (UCI) literature from a consumer perspective. The aim is to determine our current understanding/knowledge of UCI and identify areas of further research. Using a 7-stage SLR protocol, we developed a framework for categorising the UCI literature into various userrelated topics. The subsequent critical literature analysis and concluding research framework and conceptual model provide four key contributions to UCI research: (1) To identify and categorise gaps in research or knowledge relating to contemporary UCI topics; (2) To ascertain and classify contemporary empirical UCI studies; (3) To critically analyse the discussion on each of the UCI topics and (4) To derive practitioner implications from the literature review findings that will demonstrate how our understandings of the existing UCI research have practical application for industry firms.
\end{abstract}




\section{Introduction}

Many recent academic studies now acknowledge that consumers and their communities play an increasingly vital role in innovation across many markets and industries (Berthon et al., 2007; Nambisan and Baron, 2007; Payne et al., 2009; Piller et al., 2010). User-centric innovation (UCI) has emerged as a crucial strategy for organisations in terms of their survival (Desouza et al., 2008), innovation development (Greer and Lei, 2012; Janssen and Dankbaar, 2008), closer customer relations (Jespersen and Buck, 2010) and achieving best practice (Enkel et al., 2005). The purpose of this paper is to develop a greater clarity and understanding of UCI from a user perspective, through a critical and systematic analysis of both the contemporary academic literature and the associated empirical studies into UCI.

The authors define UCI as a dimension of open innovation in which the firm encourages or facilitates active participation or involvement by the end consumer in the innovation process of the product/service/idea developed and offered by the firm (Di Gangi and Wasko, 2009; Faulkner and Runde, 2009). This definition of UCI as centred on end user contributions as opposed to business-to-business (B2B) partnerships is reflected by other management scholars (Ebbesson, 2012; Gamble and Gilmore, 2013; Greer and Lei, 2012; Piller et al., 2010). Some of the authors provide alternative terminology for UCI such as cocreative innovation (Ebbesson, 2012), customer co-creation (Gamble and Gilmore, 2013; Piller et al., 2010), collaborative innovations with consumers (Greer and Lei, 2012) and crowdsourcing or crowd creation (Howe, 2009). Due to the fluid and evolving concept of UCI and the multitude of perspectives from which it can be contextualised and discussed, the authors regard the aspects of end-consumer participation, involvement and contributions as encompassing a range of distinct yet complementary consumer interactions. This aspect is supported in the management literature; for instance, Howe (2009) not only coined the term crowdsourcing but also described it as comprising four application categories of crowd 
wisdom, crowd creation or user-generated content (UGC), crowd voting and crowdfunding. Furthermore, Gamble and Gilmore (2013) proposed in their paper a typological continuum of co-creational practices that they demarcate into the concepts of viral marketing, sponsored user-generated branding, UGC, vigilante marketing and 'prosumer' marketing. The above examples indicate that these varied types of consumer interactions can be considered valid channels through which organisations can centre their innovation processes on the end consumers. The subsequent keyword searches and systematic literature review are therefore based upon these varied interactions as cited in this definition of UCI.

UCI is not a recent concept as it was first discussed in depth by von Hippel in the 1970s (Bogers et al., 2010). However, it has received a plethora of recent interest in academic literature in the digital age as more radical forms of innovation are sought on account of changing consumer preferences (Baldwin et al., 2006), more interactive marketing strategies (Wright et al., 2012) and the diversification of technology platforms and services (Laursen and Salter, 2006; Sawhney et al., 2005). The changing application of UCI within the context of management disciplines has led naturally to changing perceptions of its usefulness and relevance in the contemporary management literature (for the purposes of this paper we consider the 'contemporary literature' to be papers published since 2005).

Lettl and Gemunden (2005) assess the current significance of UCIs by stating that 'After almost three decades of research on user innovation it is widely acknowledged that users are an important actor in the innovation process' (p. 339). Despite this statement and the above literature arguments, however, the concept of UCI is not well understood (Baldwin et al., 2006; Bogers et al., 2010) or utilised in industry or policy (Hienerth and Lettl, 2011; Shah and Tripsas, 2007), and there has been a lack of empirical research that has been carried out to date regarding UCI in practice (Baldwin et al., 2006; Di Gangi and Wasko, 2009; Faulkner and Runde, 2009; Hienerth, 2006; Morrison et al., 2000). These suggestions of on- 
going uncertainty surrounding the application of UCI in practice, and the fact that it has still not been widely accepted and implemented as a valid business and management approach, highlight the need for more research into our understanding of this phenomenon.

A small number of scholars have provided tentative steps towards reviewing some of the literature; for instance, Greer and Lei (2012) critiqued some of the UCI articles from a number of different disciplines and from the context of different types of collaborations. However, their study was conducted from a purely organisational engagement perspective and the majority of the reviewed literature corresponded to B2B collaborations. Bogers et al. (2010) have made some initial progress into reviewing UCI literature from an end-consumer perspective; however, their conceptual paper is subject to a number of weaknesses such as brevity, a non-systematic approach and a lack of contemporariness (over two thirds of the literature articles they review were published prior to 2005). The authors have found that no research paper has presented a contemporary overview of the UCI literature from a user perspective in terms of what has been learned from empirical investigations, which proposed gaps in research or knowledge have been fulfilled and what is still unknown about user topics relating to UCI. So instead of reviewing a niche area within UCI topics at the expense of considering the broader perspectives of the UCI management topic, this research paper will aim to provide this contemporary, critical and systematic overview of UCI that is lacking in the recent management literature. The authors will attempt to demonstrate that we offer a useful addition to the current UCI research field through the provision of insights relating to various aspects of user benefits, communities, characteristics and motivations. In doing so, we will endeavour to develop a new and original research framework for consumer perspectives of UCI that will offer a greater clarity and structure of our knowledge and understanding of these important topics. Our intended outcome of this research framework will be to facilitate more targeted and relevant further empirical studies to address the 
important issues and challenges that have been neglected in the research to date. This research framework will also aim to develop a unique conceptual model for how our current understanding of these UCI topics have practical applications for industry practitioners; it may therefore enhance the profile of UCI as a legitimate and important business strategy for organisations and not solely an academic exercise.

On account of the lack of research, knowledge and understanding of UCI and how it can be developed and enhanced within industry, the aim of this research paper is to conduct a systematic literature review (SLR) of the UCI literature to assess our current understanding/knowledge of UCI from a user perspective and identify areas of further research. In order to achieve this overall aim, the four key objectives of this paper are:

1) To identify and categorise gaps in research or knowledge relating to contemporary UCI topics from a user perspective that have been proposed in academic journal publications;

2) To ascertain and classify contemporary empirical UCI studies from a user perspective into emergent UCI categories, contextual purposes of study and the nature/scale of the empirical data;

3) To critically analyse the discussion on each of the UCI topics in terms of research gaps that have been fulfilled, empirical studies that have driven further research on UCI and the coalition/fragmentation of the literature in linking the research gaps to the empirical investigations;

4) To derive practitioner implications from the literature review findings that will demonstrate how our understandings of the existing UCI research have practical application for industry firms. 


\section{Review methodology}

In order to address the aim and objectives of this paper, the methodology incorporated a systematic literature review (SLR) of a wide range of double-blind peer-reviewed academic journal articles. The decision to incorporate an SLR was inspired and guided by a seminal paper by Tranfield et al. (2003) in which they pioneer the benefits of using an SLR as a key tool in developing an evidence base for management research. The use of a SLR in this paper proved instrumental for developing a robust and holistic collection, synthesis and critical assessment of the present understandings of this contemporary concept of UCI, and for facilitating the emergence of the key themes and sub-themes that have formed the basis of the subsequent sections and discussions of this paper. A 7-stage SLR was conducted:

Stage 1: Keywords. A range of keywords relating to this research paper were formulated through a combination of the prior knowledge/experience of the authors in this management field, as well as a brainstorming exercise. Consideration was also given to the above acknowledgements of alternative terminology for UCI (see Ebbesson, 2012; Gamble and Gilmore, 2013; Greer and Lei, 2012; Howe, 2009; Piller et al., 2010) as well as the inherent application categories or practices (Gamble and Gilmore, 2013; Howe, 2009). This triangulation of sources resulted in initial devised keywords of 'innovation', 'consumer', 'user', 'involvement', 'control', 'interaction', ‘co-creation', 'prosumer', 'UGC', 'UCI', 'usercentric', 'viral', 'collaborative', 'contribution', ‘crowdsourcing', ‘crowdfunding' and 'crowd creation'.

Stage 2: Database search. Three distinct academic databases were utilised in order to cross-reference the results and eliminate the risk of overlooked literature. The first search was conducted through the 'Business Source Premier' database. This was chosen as the primary database as it offered the most comprehensive and wide range of business and management literature on a broad variety of themes. The search was then repeated using the databases 
'Emerald Management Extra' and 'Google Scholar.' For each search, the keywords from Stage 1 were constructed into search strings that included a combination of an article title stem search (i.e. Innovat*) and a main text body stem search (e.g. consum* OR user OR involve* OR control OR interact*). Searches were filtered (where possible) to only scholarly articles published from 2005 - 2013 in order to reduce the results to a manageable number and to remain consistent with the contemporary nature of the literature review.

Stage 3: Article scan / export. Once the database searches had wielded an appropriate amount of results, a scanning procedure was conducted by reviewing the titles and abstracts of the displayed articles for those relevant to this study. Articles were discarded if it transpired that they were not orientated to the business and management field or did not consider user perspectives, or if they were derived from unreliable sources (such as obscure or low quality journals or editorially reviewed magazines). For each germane article discovered, its bibliographical data was exported directly into Refworks for potential future referencing. The article itself was then downloaded and saved to a designated folder and labelled according to author and year of publication. In total, 88 articles were downloaded, saved and labelled in the selected folder as being potentially relevant to this study on UCI.

Stage 4: NVivo import / primary thematic coding. As soon as all of the relevant articles from Stage 3 had been collected, they were then imported into NVivo 9 as internal sources. Each article was then opened in turn and read in its entirety within NVivo. In doing this, the articles were then coded as they were being read, which proved to be more timeefficient and logical. For the coding, a two-stage process of 'axial coding' and 'selective coding' was incorporated as it was determined to be the most suitable coding method for content analysis (Carson et al., 2001; Neuman, 1994). The axial coding stage demarcated the literature into the primary themes of 'user impacts', 'user communities' and 'user behaviours' that were deemed to be applicable to the research objectives of the current study. 
Stage 5: Evaluation of nodes / new references. The procedure of Stage 4 facilitated two evaluation processes; the first of which related to the newly created nodes from the axial coding procedure. By comparing the themes derived from the primary nodes against the original keywords derived in Stage 1, new keywords discovered could then be searched through the databases and new literature added to the designated folder. The other evaluation related to new references. Through reading the literature articles in their entirety, referenced articles could be identified that were not already on the list; these could then be searched for in the databases and added to the designated folder. These two evaluation processes maintained consistency with the parameters stipulated in stages 2 by discarding new articles that were published prior to 2005. Furthermore, in accordance with the additional parameters stated in stage 3, new articles were also discarded if they were not orientated towards business and management or consumer perspectives, or were published in low quality sources. These two evaluation processes ultimately led to the addition of 39 new articles; therefore the total number of literature articles collected was eventually 127.

Stage 6: Secondary thematic coding. The coding of the literature from Stages 4 and 5 resulted in 256 UCI references from a total of 127 literature sources. For the secondary thematic identification, a selective coding process was utilised for the remainder of the primary themes. Within the primary theme of 'user impacts', two new secondary themes emerged from the selective coding procedure - 'user challenges' and 'user benefits'. Furthermore, within the primary theme of 'user behaviours', two new secondary themes emerged from the selective coding procedure - 'user motivations' and 'user characteristics'. The results of the primary and secondary coding process are shown in the SLR Framework in Table 1 that illustrates how the 256 total identified references from the SLR have been sorted and categorised into the associated primary themes and secondary themes from the 127 academic literature articles that were analysed for the study. 
Table 1. Systematic literature review framework of primary / secondary themes for literature review

\begin{tabular}{lllll}
\hline \multirow{2}{*}{ User } & Primary theme & Secondary theme & Sources & References \\
\multirow{2}{*}{ perspective } & User impacts & & $\mathbf{4 1}$ & $\mathbf{6 4}$ \\
& & User challenges & 20 & 28 \\
& & User benefits & 21 & 36 \\
& User communities & & $\mathbf{3 2}$ & $\mathbf{8 5}$ \\
& User behaviours & & $\mathbf{5 4}$ & $\mathbf{1 0 7}$ \\
& & User motivations & 31 & 67 \\
& & User characteristics & 23 & 40 \\
& & & $\mathbf{1 2 7}$ & $\mathbf{2 5 6}$ \\
\hline
\end{tabular}

Stage 7: Literature review. Each of the secondary nodes from Stage 6 provided up to seventy six references from up to forty sources, therefore providing substantial starting points for these primary and secondary themes and to be developed into the concepts that are discussed and illustrated throughout the research paper. By expanding each node in turn, a comparative analysis was then derived in order to aid the construction of the literature review as well as assisting in structuring the sections of this paper by way of the designated primary and secondary themes.

As stated above, this 7-stage SLR protocol resulted in the referencing of eighty five literature sources out of the 127 that related to UCI. Although not extensive, these eighty five sources were deemed sufficient to facilitate a thorough review of the contemporary literature on the subject. The review of this literature resulted in the identification of sixty one proposed gaps in research and eleven proposed gaps in knowledge relating to UCI. Full details of these proposed gaps are presented in Table 2 and categorised into the primary and secondary themes identified above. The proposed research/knowledge gaps will be discussed and critically analysed in the succeeding sections. 


\begin{tabular}{|c|c|c|c|}
\hline$\overline{\mathbf{U C I}}$ & Lack & Phenomenon & Author(s) \\
\hline \multirow{5}{*}{ 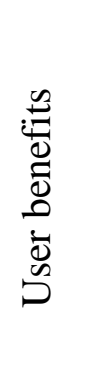 } & $\mathrm{R}$ & How users create a service for another user as a bi-directional creator & Blazevic and Lievens (2008) \\
\hline & $\mathrm{R}$ & Users as developers of commercially important innovations & Henkel and von Hippel \\
\hline & $\mathrm{R}$ & The effects of consumer empowerment on the creativity, quantity and quality of consumer & $\begin{array}{l}\text { (2005) } \\
\text { Fiiller et al (2009) }\end{array}$ \\
\hline & & contributions & \\
\hline & $\mathrm{R}$ & Does consumer involvement induce consumer interest in virtual new products? & Füller (2006) \\
\hline \multirow{8}{*}{ 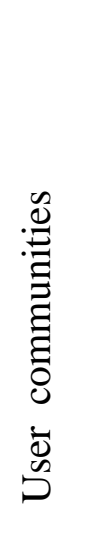 } & $\mathrm{R}$ & The interaction structures of innovation communities & Ebner et al. (2009) \\
\hline & $\mathrm{R}$ & How user communities function across a broad range of business sectors & Rowley et al. (2007) \\
\hline & $\mathrm{R}$ & Effects of community variations on the UCI process & Hienerth (2006) \\
\hline & $\mathrm{K}$ & The role of lead users and peer communities in innovations & Hienerth and Lettl (2011) \\
\hline & $\mathrm{K}$ & The overcoming of innovation process challenges in peer communities & Hienerth and Lettl (2011) \\
\hline & $\mathrm{K}$ & Joint innovation generation in online user groups & Fuller et al. (2007) \\
\hline & $\mathrm{R}$ & Complex quantitative study on online brand communities across diverse industries & Jang et al. (2008) \\
\hline & $\mathrm{R}$ & To generalize and hypothesise the operational mechanisms of online communities & Jang et al. (2008) \\
\hline \multirow{6}{*}{ 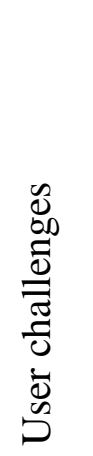 } & $\mathrm{R}$ & The profile of user communities in terms of allegiance, retention and value & Rowley et al. (2007) \\
\hline & $\mathrm{R}$ & User community processes in relation to influence, understanding and learning & Rowley et al. (2007) \\
\hline & $\mathrm{R}$ & How consumers perceive their role as a labourer for the organisation & Brabham (2008) \\
\hline & $\mathrm{R}$ & How consumers repel attempts by companies to employ them as workers & Brabham (2008) \\
\hline & $\mathrm{R}$ & $\begin{array}{l}\text { The negative aspects of how consumers observe the differences between co-located and } \\
\text { distributed settings during co-creative innovation processes }\end{array}$ & Enkel et al. (2005) \\
\hline & $\mathrm{R}$ & Quantitative study of user involvement proficiency in radical innovations & Lettl (2007) \\
\hline
\end{tabular}


R How much technological knowledge is ideal for users to ensure the technical viability of Magnusson (2009) their suggestions?

$\mathrm{K} \quad$ What motivates consumer involvement?

Brabham (2008)

$\mathrm{R} \quad$ How consumers decide if they should engage in co-production and the emotive aspects of

Etgar (2008) that decision-making process

$\mathrm{R} \quad$ The reasons why users should share their ideas and know-how with firms for NPD projects

Füller (2006)

$\mathrm{R} \quad$ Why customers choose (not) to co-create knowledge and the consequences when they wish

Blazevic and Lievens (2008) to alternate between roles?

$\mathrm{R} \quad$ What other aspects affect consumer empowerment?

Füller et al. (2009)

$\mathrm{R} \quad$ The influence of motivations on creativity, quantity and quality of user contributions

Füller (2006)

$\mathrm{R} \quad$ How users view the distinctions between co-located and distributed settings during co-

Ebbesson (2012) creative innovation processes

$\mathrm{R} \quad$ Characteristics of information used by user-innovators

$\mathrm{R} \quad$ The specific relationships between the characteristics of the customers and the types of Alam (2006) information they provide

$\mathrm{R} \quad H o w$ do consumer behaviours influence their reasons for participation?

Füller (2006)

$\mathrm{R} \quad$ The role of the user at different stages of the innovation process industries

K Aptitudes, contextual factors and characteristics of lead users

Lettl et al. (2006) 
Of the eighty five sources cited in this research paper, fifty six of the articles were based on literature reviews, theoretical discussion and/or conceptual modelling, whereas only twenty nine of the articles were based on empirical study. Furthermore, out of these twenty nine empirical articles, twenty four were derived from either secondary data (four), quantitative studies (ten) or mixed method studies (ten); only five were derived from in-depth qualitative research studies. Full details of these empirical studies are presented in Table 3 and classified into UCI categories, contextual purposes and empirical data specifics in accordance with the second objective of this research paper. These empirical studies will be discussed and critically analysed in the succeeding sections in relation to the aim and objectives of the paper.

\section{User-centric innovation from a user perspective}

The discussion of UCI in the management literature is predominantly focussed on UCI from the perspective of the firm - in terms of approaches, challenges and benefits on an internal and external scale. However, the effectiveness of this type of innovation depends also on the consumers as they are the key drivers (Hienerth and Lettl, 2011; Sawhney et al., 2005). Therefore this literature review considers the perspective of the consumer - in terms of benefits, challenges, characteristics and motivations and how they develop and organise themselves into the 'lead users' and 'user communities' in which UCI are driven (see Table 1). 


\begin{tabular}{|c|c|c|c|c|c|c|}
\hline \multirow{4}{*}{$\begin{array}{l}\text { UCI } \\
\text { category } \\
\text { User } \\
\text { benefits }\end{array}$} & \multirow{2}{*}{$\begin{array}{l}\text { Author } \\
\text { (Year) } \\
\text { Bonsu } \\
\text { and } \\
\text { Darmody } \\
(2008)\end{array}$} & \multirow{2}{*}{$\begin{array}{l}\text { Purpose of study } \\
\text { To explore co-creation's prepossessing claim of } \\
\text { consumer empowerment and its connections to } \\
\text { contemporary forms of social organization }\end{array}$} & \multirow[t]{2}{*}{$\begin{array}{l}\text { Secondary } \\
\text { data }\end{array}$} & \multirow[t]{2}{*}{$\begin{array}{l}\text { Primary data } \\
\text { Quantitative }\end{array}$} & \multirow[t]{2}{*}{ Mixed method } & \multirow[b]{2}{*}{$\begin{array}{l}\text { Qualitative } \\
\text { Participant } \\
\text { observation in } \\
\text { the virtual- } \\
\text { technology } \\
\text { context of } \\
\text { Second Life }\end{array}$} \\
\hline & & & & & & \\
\hline & $\begin{array}{l}\text { Füller } \text { et } \\
\text { al. } \\
\text { (2009) }\end{array}$ & $\begin{array}{l}\text { To investigate how consumers are empowered } \\
\text { through Internet-based co-creation activities in } \\
\text { virtual NPD }\end{array}$ & & $\begin{array}{l}727 \text { surveys to } \\
\text { co-creation } \\
\text { project users }\end{array}$ & & \\
\hline & $\begin{array}{l}\text { Harrison } \\
\text { et al. } \\
(2006)\end{array}$ & $\begin{array}{l}\text { To critically assesses the extent to which } \\
\text { consumers are being empowered by the internet, } \\
\text { focusing specifically on the role of the internet in } \\
\text { the context of online pension information } \\
\text { provision }\end{array}$ & & & $\begin{array}{l}24 \text { focus group } \\
\text { participants and } \\
\text { web page } \\
\text { analysis }\end{array}$ & \\
\hline \multirow[t]{3}{*}{$\begin{array}{l}\text { User } \\
\text { commu- } \\
\text { nities }\end{array}$} & $\begin{array}{l}\text { Hienerth } \\
\text { (2006) }\end{array}$ & $\begin{array}{l}\text { To analyze the commercialization process of } \\
\text { user innovations in open communities of product } \\
\text { manufacturing industries }\end{array}$ & & & & $\begin{array}{l}\text { 16-case study : } \\
\text { interviews with } \\
\text { user-innovators }\end{array}$ \\
\hline & $\begin{array}{l}\text { Kim } e t \\
\text { al. } \\
(2008)\end{array}$ & $\begin{array}{l}\text { To study how online brand communities are used } \\
\text { throughout the NPD process by promoting } \\
\text { communications between firms and communities }\end{array}$ & & & $\begin{array}{l}6 \text { firm case } \\
\text { studies : inter- } \\
\text { views and sur- } \\
\text { veys with com- } \\
\text { munity users }\end{array}$ & \\
\hline & $\begin{array}{l}\text { Di Gangi } \\
\text { and } \\
\text { Wasko }\end{array}$ & $\begin{array}{l}\text { To propose hypotheses based on the perceived } \\
\text { attributes of end user ideas and promotion efforts }\end{array}$ & $\begin{array}{l}\text { Analysis of } \\
6,200 \text { Dell } \\
\text { IdeaStorm }\end{array}$ & & & \\
\hline
\end{tabular}


Füller $e t$ al. (2007)

Algesheimer $e t$ al.

Antorini

et al.

Bagozzi

and

Dholakia

(2006a)

Bagozzi To conceptualize participation in Linux user

To investigate joint-development activities within online consumer groups for basketball shoes, a physical consumer product in a mature market website user

posts

graphic

study of

240,000

online

community

posts

529 surveys to

car club

members

85 hours

of

observations

3 interviews and

154 question-

naires to

members of

Harley-

Davidson

Motorcycle

SGBC, 255

questionnaires

to members of

non brand-

specific

motorcycle

riding groups 
and groups (LUGs) in terms of group-referent

Dholakia intentional actions and investigate cognitive, (2006b) affective and social determinants of participation Jang et To study the link between on-line communities al. and brands by examining how brand community (2008) characteristics affect community / brand loyalty

Bullinger To examine if and how cooperation leads to et al. innovativeness within a community-based

(2010) innovation contest run in 2009 at one of the largest universities in Germany

User

comm-

unities /

motiva-

tions

User

motiva-

tions

Casaló et To analyse the effects of involvement in a virtual al. (2008) community on consumer commitment and how consumers can be motivated to participate

Lettl and To explore under which conditions innovative Gemun- users of medical equipment start entrepreneurial den activities and become manufacturers

(2005)

de Jong To explore the crucial process by which userand von developed innovations in high-tech Dutch SMEs Hippel (2009)

Lüthje et To explain why and when mountain bike useral. innovators focus on local information

(2005)

Brabham To add qualitative data on a new crowdsourcing (2010) case to an existing body of quantitative data on
LUG members

from 23

countries

250 surveys to

community

members

215 online

surveys to

members of

virtual brand

communities

Multi-case

comparison: 45

interviews with

management

and users,

archival data

analysis

498 surveys to

Dutch hightech firms

106 questionnaires to bike club members
17 interviews via instant 
motivations for involvement in crowdsourcing

Füller To study why consumers engage in virtual NPD

(2006) initiated by producers in leisure industries

Füller et To explore how passion for the brand, affiliation al. (2008) to the brand community and trust in the brand influence the inclination to participate in a firm's innovation process

Kaiser To evaluate the impact of a blogosphere on the and impetus of lead users to develop commercial Müller- software at a large for-profit organization

\section{Seitz}

(2008)

User Füller

motiva-

tions

charact-

eristics

User

charact-

eristics
Corrocher and

Zirulia

(2010)

Jeppesen

and

Frederik-

sen (2006)
825 surveys to

virtual devel-

opment project

participants

550

questionnaires

to members of

Volkswagen

Golf GTI car

community

Multi-method

case-study:

analysis of 36

blogger posts

over 28 months

727 surveys and

20 interviews

with participants

of 10 virtual co-

creation projects

Case study : 15

interviews with

personnel from

Propellerhead

and community messenger with Threadless members 
Lettl et To explore how lead users develop radical al. innovations external to manufacturing firms in (2008) the field of medical equipment technology

Oliveira To explore the histories of 47 functionally novel Analysis of and von and significant commercial and retail banking

Hippel

(2011)

Lettl et To study which users are able to contribute to al. radical innovations in the field of medical (2006) technology and what firms can learn from them

Schreier To extend lead user theory by exploring some and antecedents and consequences of 'lead userness'

Prugl

(2008) users, online community observation, weblog data 30 interviews with lead users and managers, archival data
45 interviews with management and users

Studies

on

extreme sports

communities

(129), techn-

ical divers

(93), and kite

surfers (139) 


\section{User benefits}

Table 2 shows that the SLR for this paper identified four articles since 2005 that specifically called for research into the user benefits of UCI. These research calls include: how consumers can produce beneficial services for each other (Blazevic and Lievens, 2008); the evoking of consumer interest in virtual new product development (NPD) (Füller, 2006) and the effects of consumer empowerment on the creativity, quantity and quality of consumer contributions (Füller et al., 2009). Henkel and von Hippel (2005) called for a study into how consumers can benefit from developing innovations that are commercially important. Interestingly, Table 3 shows that this proposed research was conducted later in the same year by Tietz et al. (2005) in their mixed method study on 'novel products' developed by consumers and also the following year by Hienerth (2006) in a qualitative case study that analysed the commercialisation process of these user innovations. Table 3 also shows that three other empirical studies on user benefits have also recently been carried out - all of which are focused on consumer empowerment from the perspectives of contemporary social firms (Bonsu and Darmody, 2008) or Internet-based co-creation activities (Füller et al., 2009; Harrison et al., 2006). They also pre-date the research call into consumer empowerment by Fuller et al. (2009) who cite two of these empirical studies in their article before calling for further research into the additional perspectives mentioned above.

In an empirical study Hienerth (2006) concluded that user-innovators incur less time and costs associated with developing new ideas into innovations, and that they also benefit from potentially strong user communities where skills can be interchanged and combined prior to UCI development. This would suggest that users could incur benefits much earlier in the UCI process than suggested by Henkel and von Hippel (2005) - who argue that lead users are incentivised by anticipated economic or personal benefits associated with the development stage of the innovation. Füller (2006) has defended the viewpoint of Henkel and 
von Hippel in his own conceptual paper in which he maintained that 'Consumers participating in virtual new product developments will rarely be able to benefit immediately from using “their" innovation' (p. 639). However, in a subsequent paper three years later involving a large-scale quantitative study into online consumer empowerment, he concluded that as well as benefitting from contributing to early-stage NPD on account of their sense of importance, mastery and meaning, but that this perceived empowerment also enhances their motivations to repeat tasks and/or participate in subsequent projects (Füller et al., 2009).

The association of user innovations with lower costs at the 'experimentation' stage is supported by other scholars (Lüthje, 2004; Oliveira and von Hippel, 2011). However, in later stages of the UCI process, users may be presented with a financial dilemma. If they choose to conceal their innovation, von Hippel (2007) has suggested that the financial investments required to secure intellectual property rights may offset the financial benefits of developing the innovation at a low cost at the 'experimentation' stage. However, this argument neglects to consider the potential additional financial benefits, as in some documented cases users may also earn a wage that is commensurate with the competitiveness of the situation when they participate in UCI (Kleemann et al., 2008). More research is needed in this area and there may actually be a negative correlation between investment and benefit, whereby the introduction of user communities can facilitate greater benefit from UCI with minimal investment from the individual user.

\section{User communities}

Table 2 suggests that user communities are a sub-topic of UCI in which academics are particularly interested in developing greater knowledge and understanding; since 2005 there have been ten calls for further research into aspects of user communities including their interaction and working structures (Ebner et al., 2009; Jang et al., 2008; Rowley et al., 2007); 
how they operate over various business sectors and industries (Jang et al., 2008; Rowley et $a l ., 2007)$ and the impact of community changes on the UCI process (Hienerth, 2006). Some further studies have examined the role of lead users and the overcoming of innovation barriers within communities (Hienerth and Lettl, 2011) and the community profiles with regard to value, retention and loyalty (Rowley et al., 2007).

The call for research by Rowley et al. (2007) has subsequently been addressed by Jang et al. (2008) in their survey-based study on how community characteristics influence commitment and loyalty within the community. Their findings not only corroborated prior studies by concluding that community commitment enhances brand loyalty from the users, but also advised that increased community commitment may improve financial performance for practitioners by way of word-of-mouth marketing and consumer rephrasing. A similar approach was taken by Casaló et al. (2008) in their quantitative study of the effects of community participation on consumer commitment. They also confirmed how participation positively affects brand commitment, whilst emphasising how virtual communities represent authoritative tools to strengthen managerial ties. They therefore advised that firms should stimulate communication and group unity within these communities so as to incite community member interactions, while additionally satisfying consumer needs and establishing long-term sustainability for the community.

The call for research into overcoming innovation barriers within communities by Hienerth and Lettl (2011) has been addressed by Di Gangi and Wasko (2009) in a large-scale secondary study on the barriers of balancing decision-making powers within user communities. It was also addressed by Bullinger et al. (2010) in their multiple-case study on how co-operation with innovation contests can lead to innovations within user communities. In this latter study, their findings identified subtypes of proactive and reactive community boundary spanning, whilst concluding that organisers of innovation contests should ensure 
that the design represents individual drivers in order to achieve proactive boundary spanning. They also proposed that the attainment of highly innovative submissions from individuals is dependent on organisers designing contests that accommodate users with high levels of competitive orientation. The remaining eight calls for research have not been answered by empirical studies and the remaining seven empirical studies shown in Table 3 have instead concentrated on other aspects of consumer communities such as: the commercialisation process of innovations in communities (Hienerth, 2006); how communities are used throughout the NPD process (Füller et al., 2007; Kim et al., 2008) and consumer relationships and behaviour with/within user communities (Algesheimer et al., 2005; Bagozzi and Dholakia, 2006a; Bagozzi and Dholakia, 2006b).

The emergence of user communities provides a strong catalyst for on-going user innovations as it shows how the triangulation between experimentation, innovation and user communities can lead to positive innovation outputs when shared back with the organisation or developed as a new product of service for the users (Henkel and von Hippel, 2005; Jeppesen and Frederiksen, 2006). The significance of these communities is acknowledged in the management literature with discussions concerning various aspects of their existence and impact on UCI (Baldwin et al., 2006; Di Gangi and Wasko, 2009; Hienerth and Lettl, 2011; Jeppesen and Molin, 2003). However, despite a lack of empirical research to support their claims, there have been suggestions by Baldwin et al. (2006) that in actuality some industries - manufacturing in particular - are lacking a systematic analysis of NPD opportunities that user communities represent. A multiple case study two years later by Kim et al. (2008) addressed this issue and found that the promotion of communications between firms and communities can help capitalise on NPD opportunities by ascertaining strengths and weaknesses of new products whilst germinating brand loyalty. In terms of managerial implications from the findings, they advised that firms should implement relevant strategies 
to not only initiate user involvement at various NPD stages, but also to maintain relations with key individuals that exhibit high loyalty or influence qualities.

Hienerth and Lettl (2011) have raised the question of when and how innovations developed within user communities may be diffused to external stakeholders. However, they have neglected to cite preceding empirical work that addresses this question; Kim et al. (2008) for instance have analysed the use of communication strategies between firms and communities and one of their findings was that ' $\mathrm{OBCs}$ can be platforms for the firms' communication channels with customers and society' (p. 373). Furthermore, Antorini et al. (2012) conducted observation studies into how Lego work with external communities. Their results demonstrate that, where community users who participate on the development team work for related firms, mutually beneficial partnerships between the host organisation and the external stakeholder have been documented. For firm-initiated communities in particular, they may be able to monitor the community activities or maintain confidence in the likelihood of diffusion on account of the previously mentioned incentivisation (Jeppesen and Frederiksen, 2006). However, the risks of concealment within the community may also be mitigated by the prospect that the increased adoption of innovations may reduce uncertainty for external users and therefore accelerate innovation diffusion (Hienerth and Lettl, 2011).

As user communities rely so prominently on the relationships and characteristics of the users within, Balwin et al. (2006) have suggested that there is a fundamental and potential weakness in terms of benefits to the community if rivalry or negative tensions emerge between community users. Not only is this suggestion logically sound but it also validates the proliferation of empirical studies that have either studied behaviour determinants in different community sizes (Bagozzi and Dholakia, 2006a), developing conceptual models relating to intentions (Algesheimer et al., 2005), or investigated cognitive, affective and social participatory consequences (Bagozzi and Dholakia, 2006b). User communities also constitute 
a significant risk to firms on account of the substantial resource requirements for firms to participate in and support community activities, according to a netnographic study by Dahlander and Wallin (2006). However, they did not consider a number of other potential risk factors that have been more recently proposed by Di Gangi and Wasko (2009) through their similar in-depth netnographic study into online user communities. They highlighted risks relating to a lack of control over the innovative content, which they argued could potentially result in 'public forum for customer complaints that could generate very bad

publicity for the firm' (p. 304). Moreover, they proposed that there also exists the potential for conflict between the user innovation community and the host firm if the community becomes more closely integrated with the processes of the firm. Therefore, user communities may be volatile and hence it is important that relationships are maintained and nurtured - not only within the community but also between it and the firm in which the innovations were originally derived (Di Gangi and Wasko, 2009).

\section{User challenges}

Aside from the issues mentioned above regarding user innovations within defined communities, there are other challenges facing UCI in practice that must be considered. Table 2 shows five calls for research into the challenges that users face in becoming involved in UCI. These calls refer specifically to perceptions of the user as a 'labourer' for the company (Brabham, 2008), as well as referring to the users' perceptions of co-located or distributed settings during the UCI process (Enkel et al., 2005). Furthermore, there are calls for a quantitative examination of the optimum competence levels for consumer involvement in radical innovations (Lettl, 2007) as well as the ideal knowledge levels for ensuring technical viability (Magnusson, 2009) and how users can oppose attempts by firms to manipulate them 
(Brabham, 2008). Despite all these calls for research, however, no empirical studies have been conducted since 2005 that address any of these research gaps.

The management literature does provide discussion around the challenges facing consumers who engage in UCI activities - especially in the early stages. For instance, a qualitative study by Kristensson et al. (2008) into proactive firm approaches found that technology service users quite often lack the capacity to anticipate and/or articulate their service innovation ideas on account of their limited technological knowledge. These results are supported by a quasi-experimental study into firm benefits of UCI by Magnusson (2009) that also concludes that 'ordinary users' lack the level of technical know-how to propose implementable ideas relating to technology-based services prior to the firm's introduction of the technology. Consequently, they conclude that the inclination of ordinary users to contribute either radical or incremental ideas is proportional to their understanding of the underlying technology. They therefore advise that industry practitioners should become aware that providing a guided approach to informing users of these technologies may result in an increase in practicable suggestions, but may also incur a reduction in the originality of the ideas. These insights raise interesting suggestions relating to the distinction between these 'ordinary users' and the user-innovators and lead users and their respective challenges. This is further supported by Lettl et al. (2006) whose qualitative empirical study concluded that 'Studies on the implementation of the lead user method may have a positive bias towards the role of users' (p. 254). The authors would recommend further empirical study to address this under-developed UCI topic.

For other authors, however, the user challenges are derived not from their actual limitations but from their perceptions of the challenge. For example, Piller et al. (2005) conducted a mixed method study into online communities in which they found that it was the perceived complexities, efforts and risks for the consumer that limited the success of mass 
customisation strategies. Consequently, they have advised practitioners that one of the most fundamental tasks is to clarify and emphasise the benefits of obtaining a customised solution to the potential user-innovators, whilst simultaneously propagating user perceptions of low expenditure rates. At the later stages of the UCI process, Zwick et al. (2008) argue that, just as the firm has to contend with an initial loss of control over the innovation, the consumer will also lose control once it returns to the organisation. This is actually significant when coupled with the potential extended time period between the innovation being shared back with the firm and it eventually emerging on the market. Other alternative versions of the same innovation may arise if the innovation concept is leaked from the firm (von Hippel, 2001; von Hippel, 2007). However, Henkel and von Hippel (2005) suggest that if user innovations are concealed from the firm they may actually be more vulnerable to duplicative work, and would also be negatively affected by the lack of subsequent innovations arising from the concealment from the originating firm. In summary, the main user challenges of UCI are presented in Table 4.

In reality, the exact challenges facing each user in the UCI will be individualistic on account of the context-specific nature of each organisation and its innovation practices (Füller, 2010; Tietz et al., 2005). However, on account of the above discussion regarding the distinct firm approaches to UCI, it may be possible to determine the likelihood of the firm's propensity to invest user-benefitting resources into the UCI process based on firm characteristics associated with the two identified firm approaches (Franke et al., 2006). 


\begin{tabular}{|c|c|c|}
\hline Challenge & Description & Rationale \\
\hline Delays & $\begin{array}{l}\text { A prolonged delay for users before they can access - and } \\
\text { benefit from - their co-created innovation (Henkel and von } \\
\text { Hippel, 2005) }\end{array}$ & $\begin{array}{l}\text { Further time required to transform virtual innovations into a } \\
\text { developed product / service for the end market }\end{array}$ \\
\hline Control & $\begin{array}{l}\text { User control loss once innovation returns to organisational } \\
\text { space (Di Gangi and Wasko, 2009) }\end{array}$ & Firm regains control of innovation \\
\hline Technology & $\begin{array}{l}\text { Possible access barriers to computers, Internet and high- } \\
\text { speed connections (Brabham, 2008) }\end{array}$ & $\begin{array}{l}\text { Involvement is reliant on ease and convenience of } \\
\text { technological access - particularly for virtual UCI }\end{array}$ \\
\hline Social / legal & $\begin{array}{l}\text { Negative perceptions of 'hacking' as well as legal / } \\
\text { contractual difficulties (Braun and Herstatt, 2007) }\end{array}$ & $\begin{array}{l}\text { The prospect of having to acquire 'licenses to innovate' may } \\
\text { discourage users }\end{array}$ \\
\hline $\begin{array}{l}\text { Knowledge } \\
\text { limitations }\end{array}$ & $\begin{array}{l}\text { With technology-based services, users may not be able to } \\
\text { anticipate or express their innovation ideas (Kristensson et } \\
\text { al., 2008) }\end{array}$ & $\begin{array}{l}\text { In knowledge-intensive industries the potential for user- } \\
\text { innovators is restricted in terms of ability to create value }\end{array}$ \\
\hline
\end{tabular}




\section{User motivations}

With the substantial challenges facing users who contemplate involving themselves in UCI, it is also contextually relevant to consider their motivations in order to place their strategic decision-making into perspective (Piller and Walcher, 2006). The SLR for this paper resulted in eight proposed gaps in research or knowledge relating to user motivations for participating in UCI that are displayed in Table 2. Specifically, these calls were associated with which variables influence consumer empowerment (Füller et al., 2009); the impact of various motivations on consumer contributions in terms of creativity, quantity and quality (Füller, 2006); how consumers actually decide whether or not to engage in co-production (Etgar, 2008) and why they choose whether or not to co-create and share knowledge (Blazevic and Lievens, 2008) - especially for purposes of NPD (Füller, 2006).

Table 3 shows that nine empirical studies have been carried out into user motivations since 2005; of which five have been quantitative in nature, three have been mixed method studies and only one was purely qualitative in nature. However, none of these empirical studies have addressed any of the eight proposed research gaps and have instead examined other aspects of UCI such as how consumers can be induced to participate in virtual communities (Casaló et al., 2008) or virtual NPD (Füller, 2006) and how these motivations influence their expectations of virtual co-creation (Füller, 2010). This latter study identified a typology of four distinct kinds of consumers who engage in co-creation and concluded that not only do consumer motivations define their expectations towards virtual co-creation, but also that diversely motivated users differ substantially in terms of personality. Other UCI studies into user motivations have addressed the factors that affect consumer decisions regarding the transfer of UCIs to the organisation (de Jong and von Hippel, 2009); the reasons for user-innovators to concentrate on local information (Lüthje et al., 2005); motivations for participating in crowdsourcing (Brabham, 2010); how consumer 
passion/loyalty towards a brand or brand community affects willingness to engage in the innovation process (Füller et al., 2008) and the influence of a blogosphere on lead user motivations (Kaiser and Müller-Seitz, 2008). This final study by Kaiser and Müller-Seitz (2008) found that intrinsic motivations can be cultivated by weblog technology as users are permitted to express their views openly in a collaborative and trustworthy setting. It also concluded that extrinsic motivations can be cultivated by the expectation of boosting user reputations within the community.

The discussion of user motivations for UCI in the management literature suggests that they are difficult to compare because they depend exclusively on the context of the particular innovation and the user's intention regarding its development (Jeppesen and Frederiksen, 2006). For instance, Baldwin et al. (2006) have suggested that for design-related innovations, users are motivated to explore the design space as they believe that the new designs that may arise out of the innovation will enhance their own design skills. Therefore, the prospect of personal skills development, as a direct result of the innovation, may represent the motivation as well as the start of a stream of related new products. Faulkner and Runde (2009) have asserted that, additional to ingenuity as the most significant input for users wishing to innovate, time and passion for the subject also represent key related motivational factors.

De Jong and von Hippel (2009) believe that individuals are often motivated to innovate on account of their 'ahead-of-market' needs. This belief is validated by their indepth quantitative empirical study into this aspect and suggests a more practically-orientated need to solve a problem that the closest product/service on the market is inadequate to solve. It is also interesting as the vast majority of the population, at some point in the course of their lives, may find themselves in this situation; ergo any consumer has the potential to be selfmotivated to become a user-innovator (Oliveira and von Hippel, 2011). However, Franke et al. (2006) conducted a mixed method empirical examination of lead user theory; they 
concluded that for these 'ahead-of-the-market' needs to constitute a motivation for UCI there may also exist a lack of personal resources relating to this need. Therefore, one must acknowledge the 'push' factors relating to the positive aspect of the motivation, for example personal development or skills enhancements as mentioned above (Baldwin et al., 2006; Faulkner and Runde, 2009; Füller, 2010; Henkel and von Hippel, 2005). In a recent qualitative study on crowdsourcing by Brabham (2010) he provides a long list of these opportunistic 'push' factors such as revenue generation, creative skills development, selffulfilment, freelance design work leverage, community enjoyment and addiction. However, he also concludes that 'there is no definitive set of motivators that works for all crowdsourcing cases' (p. 1139). This statement is perhaps echoed by the views of Janssen and Dankbaar (2008) in which they express that from the specific context of high-tech radical new product innovations, consumer involvement in the development process is driven by a “technological push" (p. 523). Consequently, they argue that the utilisation of a consumer perspective to construct the technology constitutes a significant reason for practitioners to involve the consumers.

A structural argument of user innovation motivations is proposed by Füller (2010) whose mixed method empirical study identified a number of different singular motivations and grouped them into 'purely intrinsic,' 'internalised extrinsic' and 'purely extrinsic.' Based on the above discussion, these motivations may be considered positive 'push' factors that drive the user towards co-creational innovation and neglect to acknowledge the polarising negative 'pull' factors. Therefore, the user motivations to innovate should not always be considered in terms of positive push factors but that users may actually feel 'pulled' into the UCI process. This is arguably on account of some of the negative factors such as isolation from users of the product/service, the need to become more socially acceptable on account of a low social standing, or the desire to counterbalance a history of low achievement or 
financial standing (Füller, 2010). In a study on open source community collaborations with commercial software companies, Agerfalk and Firzgerald (2008) have emphasised the multifaceted nature of UCI pull factors and how they should not be underestimated. They explain that 'there are forces in the ecosystem pulling in opposite directions: while cost-savings and innovation are facilitated by a large unknown workforce, trust-building and recruitment of community developers by the customer will tend to erode the unknown aspect' (p. 403).

Some of these aforementioned pull factors are cited in the wider management literature. For instance, Henkel and von Hippel (2005) have stated that 'To avoid the welfare loss this entails, public policy should think about how to strengthen users' incentives both to innovate and to freely reveal their innovations' (p. 19). Hienerth (2006), who empirically analysed the commercialisation process of user innovations, has also hinted at the possibility that he has considered both the positive 'push' factors and the negative 'pull' factors of UCI motivations. He suggested that users, who act in a variable and informal custom, do not innovate on account of specific objectives for commercialisation but instead due to their needs and their problem orientation. Indeed, the writers would concur that the 'pull factors' could be considered problem-orientated motivational factors. The aforementioned mixed method study by Franke et al. (2006) found that an aspect of their lead user definition relating to being at the cutting edge of a marketplace trend - indicates both innovation attractiveness for users and their likelihood to participate in UCI. They also concluded that, ultimately, the motivations for each user are entirely idiosyncratic and personally specific.

The results of an empirical mixed method study by Jeppesen and Frederiksen (2006) into user characteristics reveals that recognition from the originating firm is a key motivating factor for users to innovate within user communities, and that the attainment of this recognition is associated with perceptions of self-pride and self-benefit for the participating users. They suggest that this recognition may explain what attracted the users to the 
community in the first instance and what incites them to share their innovations thereafter, and that in terms of strategic direction it may be advisable for management to 'allocate' recognition tactically so as to motivate certain key users. This viewpoint is supported by Füller (2006) in his quantitative examination into this phenomenon from the context of virtual NPD. He revealed that the consequences of consumer engagement such as recognition may constitute a motivating factor that is as important as the interest in the interaction itself. His study demonstrates the significance of considering user characteristics as well as their motivations for participating in UCI.

\section{User characteristics}

With the recognition that users may be motivated to innovate through a combination of push/pull factors as well as intrinsic/extrinsic factors, it is necessary to consider the characteristics of user-innovators to further explore and understand their rationale behind their involvement in UCI (Füller, 2010; Lüthje and Herstatt, 2004). The SLR for this paper has identified seven gaps in research or knowledge relating to user characteristics that have been proposed since 2005 (see Table 2). These gaps relate to users' abilities to perceive differences between distributed and co-located settings during the UCI process (Ebbesson, 2012); the relationship between user characteristics and the kinds of information they present during the UCI process (Alam, 2006) and how their characteristics impact upon their motives for participating (Füller, 2006). Additional identified research gaps correspond to the consumer's role at different stages of the innovation process (Laursen, 2011); a substantial quantitative study into the entrepreneurial role of consumers across different industries (Lettl and Gemünden, 2005) as well as the behaviours and competencies of lead users (Lettl et al., 2006). 
Table 3 shows that six empirical studies have been conducted into user characteristics since 2005. Two of these studies were based on secondary data and two were mixed method studies; there was only one single quantitative study and one single qualitative study during this period. The research gap proposed by Lettl (2006) relating to lead user behaviour has been partially addressed by Lettl et al. (2008) in their mixed method study into this phenomenon from the context of manufacturing firms. Their findings reveal that lead users offer a wider range of contributions and knowledge due to their diversification of unanticipated roles, and that manufacturing companies can maximise this potential through the development of contemporary types of integration and interaction. The research gap proposed by Lettl (2006) has also been fully addressed by Schreier and Prugl (2008) in their quantitative study on the characteristics and consequences of users' 'lead userness'. Their empirical results concluded that lead users exhibit an elevated internal locus of control, tend to have innovative personalities and therefore adopt new products quicker and more seriously than average users. Consequently, Schreier and Prugl (2008) advise that their findings relating to field-dependent and field-independent variables may improve the lead user research process for practitioners through narrowing the search field and the employment of pyramiding to detect lead users.

Furthermore, the research gap proposed by Alam (2006) above has been addressed by Lettl et al. (2006) in their qualitative study on both user characteristics and what firms can learn from them during their participation. Their findings indicated that the ascertained traits of creative users can be utilised by manufacturing firms to identify future creative users, which can subsequently enhance the creative aptitude of the practitioners through the attainment of radically new solutions or ideas. However, the remaining five proposed research gaps relating to user characteristics have not been fully addressed to date and the remaining five empirical studies have addressed various other issues related to user 
characteristics. These issues include the relationship between new tariff plan development and consumer behaviour (Corrocher and Zirulia, 2010), the creation of value on account of consumer attributes (Jeppesen and Frederiksen, 2006) and consumers' self-providing characteristics (Oliveira and von Hippel, 2011).

Regarding the discussion in the management literature of specific user characteristics that inform their interest in certain stages of the UCI process, Füller (2010) empirically analysed how user personalities influence their expectations of virtual co-creation. He concluded that for some users it is the creation of new ideas or solutions, whereas for others it is the evaluation and selection of innovation concepts. This viewpoint is supported by an interview-driven case study by Hienerth (2006) who argues that user-innovators usually have a direct personal need regarding the innovation, but no actual commercial interest in the developed innovation. However, as discussed, this is not always the case and many users have proceeded to develop commercial products or services out of their innovations (Baldwin et al., 2006; de Jong and von Hippel, 2009; Franke et al., 2006).

The above cited personal needs, as expressed by Hienerth (2006), demonstrate the inquisitive nature of user-innovators and their proactivity to actually fulfil the need that is not satisfied by the current product/service. Jeppesen and Frederiksen (2006) argue that the characteristics associated with these personal needs may be said to represent a hobbyist status as opposed to a professional status for the user with respect to commercial desires; this argument is substantiated by their mixed method case study into personal attributes of userinnovators. Therefore, in any given industry or firm it may be of importance to identify whether the users who follow their products/services have the potential to become userinnovators and maintain a hobbyist status or professional status regarding their characteristics (Jeppesen and Frederiksen, 2006; Shah and Tripsas, 2007). This approach could potentially lead to a more structured direction for executing a strategy aimed at developing UCI through 
a proactive firm approach (Shah and Tripsas, 2007). Oliveira and von Hippel (2011) empirically investigated user innovations in the banking sector through secondary data analysis. Their findings provide another interesting yet anecdotal dimension to the discussion by emphasising the importance of not only the type of need but also the accuracy and detail of the needs exhibited by potential user innovators. This aspect of increased accuracy and detail of the needs may be arguably linked to associations of user-innovators with heightened desires and innovation-related knowledge (Tietz et al., 2005).

Other academics have also commented on how user characteristics can evolve and change depending on which stage of the UCI process they are involved with. Lettle et al. (2006) offer empirical research results from a multiple case-study analysis that suggest that some user-innovators can often exhibit the characteristics of an inventor or co-developer of the product or service. However, their findings also caution that additional characteristics will be required in order to maximise user contributions to radical innovations. These additional cited attributes include receptiveness to new technologies, strong intrinsic motivations and reflective of a supportive environment.

\section{Conclusion}

The aim of this research paper was to provide a contemporary overview of the UCI academic research papers published since 2005 in terms of providing greater clarity of our current understanding of the key topics and sub-topics within UCI from a user perspective. As a summary of all the tables and critical discussion provided throughout the paper on account of the SLR, Table 5 has been formulated as a research framework to help future UCI researchers navigate the complex network of research that has been carried out over this time period and to assist in developing more structured and focussed research questions for relevant future investigations in the field of UCI. 


\begin{tabular}{lllllll}
\hline UCI topic & $\begin{array}{l}\text { Areas } \\
\text { study }\end{array}$ & addressed & by & empirical Key findings from empirical studies & $\begin{array}{l}\text { Unanswered gaps in research / } \\
\text { knowledge }\end{array}$
\end{tabular}

User

benefits

- 'Novel products' developed by consumers (Tietz et al., 2005) user innovations (Hienerth, 2006)

- Consumer empowerment from the context of new social firms (Bonsu and Darmody, 2008) or Internet-based co-creation activities (Füller et al., 2009; Harrison et al., 2006)

User communities

- How community traits affect commitment and loyalty in the community (Jang et al., 2008)
- The commercialisation process of

- User-innovators incur less time and costs when developing new ideas into innovations, (Hienerth, 2006)

- Users contribute to early-stage NPD due to their sense of significance, mastery and meaning, which enhances their motivation to repeat tasks and therefore continue to benefit from front-end UCI (Füller et al., 2009)

- Users may benefit financially from company wages proportionate to the competitiveness of the UCI activity (Kleemann et al., 2008)

- The effects of community involvement on consumer commitment (Casaló et al., 2008)

- The challenges of managing decision-making powers within user communities (Di Gangi and Wasko, 2009)

- How co-operation with innovation contests can result in innovations in user communities (Bullinger et al., 2010)

- The commercialisation process of innovations within user
- The promotion of communications between firms and communities can help maximise NDP opportunities (Kim et al., 2008)

- User communities constitute a risk to firms due to the sizable resource needs for firms to partake in and assist community activities (Dahlander and Wallin, 2006)

- There would be a lack of control over UCI content and conflict between the community and the firm (Di Gangi and Wasko, 2009)

- Enhanced community commitment may increase firm fiscal performance due to wordof-mouth marketing (Rowley et al., 2007)

- Firms should incite communication and group unity within communities to facilitate community member interactions, satisfy
- How users can create beneficial services for each other (Blazevic and Lievens, 2008)

- The evoking of consumer interest in virtual NPD (Füller, 2006)

- The effects of user empowerment on the creativity, quantity and quality of user contributions (Füller et al., 2009)

- Community interaction and working structures (Ebner et al., 2009; Jang et al., 2008; Rowley et al., 2007)

- How communities operate across different business sectors and industries (Jang et al., 2008; Rowley et al., 2007)

- The effects of community changes on the UCI process (Hienerth, 2006)

- The role of lead users within user communities (Hienerth and Lettl, 2011) 
communities (Hienerth, 2006)

- How communities are used during the NPD process (Füller $e t$ al., 2007; Kim et al., 2008)

- Consumer relationships and behaviour with/within user communities (Algesheimer et al., 2005; Bagozzi and Dholakia, 2006a; Bagozzi and Dholakia, 2006b)

User

challenges consumer needs and establish long-term sustainability (Casaló et al., 2008)

- The fulfilment of innovative creations from users is reliant on organisers designing contests that assist users with a high rate of competitiveness (Bullinger et al., 2010)

- Where community users work for associated firms, beneficial partnerships between the host firm and external firm have been documented (Antorini et al., 2012)

- Technology users often lack the ability to anticipate their service innovation ideas due to their limited technological knowledge (Kristensson et al., 2008; Magnusson, 2009)

- Practitioners providing a guided approach to informing users of technologies may result in more attainable - but less original - ideas (Magnusson, 2009)

- One of the most important goals is to explain and emphasise the benefits of attaining a customised approach to user-innovators, whilst propagating user perceptions of low expenditure levels (Piller et al., 2005)

User motivations

- How consumers can be induced to participate in virtual communities (Casaló et al., 2008) or virtual NPD (Füller, 2006)

- How motivations influence user
- Users are motivated to innovate due to their 'ahead-of-market' needs (de Jong and von Hippel, 2009) and problem orientation (Hienerth, 2006)

- There may also be a lack of personal
- Perceptions of users as 'labourers' for the firm (Brabham, 2008)

- Users' perceptions of co-located or distributed settings during the UCI process (Enkel et al., 2005)

- Quantitative study of competence levels for user involvement in radical innovations (Lettl, 2007)

- Optimum knowledge levels for ensuring technical viability (Magnusson, 2009)

- How users can oppose attempts by firms to manipulate them (Brabham, 2008)

- Which variables influence user empowerment (Füller et al., 2009)

- The impact of different motivations on user contributions in terms of creativity, quantity and 
expectations of virtual cocreation (Füller, 2010)

- What affects user decisions on the transfer of UCIs to the firm (de Jong and von Hippel, 2009)

- The reasons for user-innovators to focus on local information (Lüthje et al., 2005)

- Motivations for participating in crowdsourcing (Brabham, 2010)

- How consumer interest/loyalty towards a brand or community affects willingness to engage in the UCI (Füller et al., 2008)

- The influence of a blogosphere on lead user motivations (Kaiser and Müller-Seitz, 2008)

User

charac-

teristics context of manufacturing firms (Lettl et al., 2008) resources relating to 'ahead-of-market' needs (Franke et al., 2006)

- Acknowledgment from the firm is a main motivating factor for users to innovate in communities and is associated with selfperceptions of pride and benefit for users (Jeppesen and Frederiksen, 2006)

- The results of consumer engagement such as acknowledgment may represent a motivating factor that is as crucial as the interest in the interaction itself (Füller, 2006)

- Intrinsic motivations can be nurtured by blog technology as users are able to express views openly in a cooperative and trustworthy setting (Kaiser and Müller-Seitz, 2008)

- Lead user behaviour from the

- The characteristics and consequences of users' 'lead userness' (Schreier and Prügl, 2008)

- User characteristics and what firms can learn during their involvement (Lettl et al., 2006)

- The link between tariff plan development and user behaviour (Corrocher and Zirulia, 2010)
- User-innovators often have a personal need for the innovation, but no genuine commercial interest (Hienerth, 2006)

- Personal needs show the inquisitive nature of user-innovators and their proactivity to fulfil this need that is not satisfied by the current product/service (Hienerth, 2006)

- The traits associated with personal needs may represent a hobbyist status for the user regarding commercial desires (Jeppesen and Frederiksen, 2006)

- The importance of not only the type of need quality (Füller, 2006)

- How users decide (not) to engage in co-production (Etgar, 2008)

- Why users choose whether or not to co-create and share knowledge (Blazevic and Lievens, 2008) especially for purposes of NPD (Füller, 2006)

- Users' abilities to perceive distinctions between distributed and co-located settings during the UCI process (Ebbesson, 2012)

- How user traits affect their motives for participating (Füller, 2006)

- The users' role at various stages of the UCI process (Laursen, 2011)

- A quantitative study into the entrepreneurial role of users across diverse industries (Lettl and Gemünden, 2005) 
- The generation of value due to consumer attributes (Jeppesen and Frederiksen, 2006)

- Consumers' self-providing characteristics (Oliveira and von Hippel, 2011) but also the accuracy and detail of the needs exhibited by potential user innovators (Oliveira and von Hippel, 2011)

- Some user-innovators can display the behaviours of an inventor or co-developer of the product/service. The traits of creative users can be used by firms to identify future creative users (Lettl et al., 2006)

- Lead users offer contributions and knowledge due to their eclectic roles; manufacturing firms can maximise this potential via the growth of new kinds of integration and interaction (Lettle et al., 2008)

- Field-dependent/independent variables may enhance the lead user research process for firms by narrowing the search field and employment of pyramiding to detect lead users (Schreier and Prugl, 2008) 
The first objective of this paper was to identify and categorise the gaps in research or knowledge relating to UCI topics that have been proposed in academic journal publications since 2005. This task is summarised in Table 2 with a comprehensive and detailed depiction of all the proposed research/knowledge gaps and categorised in accordance with the perspectives and themes identified in the SLR protocol. These gaps were then critically discussed throughout the paper and the final summary of the remaining research gaps are presented in Table 5. In total there are twenty remaining research gaps and these are consistent across all of the themes discussion throughout the paper with at least four research gaps still existing in most categories. In particular, we observe that the UCI topics of user challenges are in most urgent need of empirical research as we have identified a significant number of valid research gaps in these topics in comparison to the empirical studies that have been carried out. This research framework will therefore be instrumental in guiding future researchers towards the most appropriate research gaps to address from the context of what empirical studies have already been conducted and what insights the recent empirical findings provide.

The second objective of this research paper was to determine and classify the empirical research relating to UCI topics that have been conducted since 2005. This was presented in Table 3, which provides three levels of classification of these empirical studies. The first level of classification corresponds to the arbitrarily defined UCI categories that emerged from the SLR protocol; these categories classified the empirical papers into four user benefit studies, ten user community studies, one user community/motivations study, seven user motivations studies, one motivations/characteristics study and six characteristics studies. Some of these overlap categories were designed to classify examples of empirical UCI studies that are conceptually positioned at the interface between two categories. The second level of classification corresponded to the purpose of each empirical study, which 
provided contextual positioning for each study in terms of its industry/sector and which research gap it was addressing. The third level of classification corresponds to the nature of the empirical data in which it demarcates and details the secondary or primary data for each study. Within primary data, there is a further demarcation into quantitative, mixed method or qualitative studies. This third level of classification provide further contextual positioning of the studies by detailing the industry/sectors of the any interviewees or survey respondents, as well as their employment role within the company or community being studied. Lastly, this level of classification also offers insight into the scope and scale of each study by detailing the amount of data collected. The information on these empirical studies that was classified and presented in Table 3 was critically analysed throughout the paper and then summarised in Table 5. In total there were forty areas of UCI empirically investigated since 2005; however, these were not consistently dispersed across all of the themes identified in the SLR protocol. Table 5 illustrates that some areas such as user motivations and user communities have received up to seven distinct areas of empirical study, whereas other areas such as user challenges received just one investigation or none at all. The table also shows the areas that have been addressed by up to four separate empirical studies since 2005 . Therefore, the findings presented in table 5 should be helpful for future UCI researchers in terms of directing them to the areas that are lacking in empirical research and helping them avoid the areas that are already saturated with multiple studies.

As a further guideline to assist future research, Table 6 has been formulated to illustrate and categorise all of the empirical studies conducted into UCI since 2005 in terms of the academic journals in which they appear. From this table, researchers will be able to view at a glance which types of journal are publishing which types of studies and from which of the thematic UCI categories discussed throughout this paper. This may be beneficial in terms of helping future researchers to target their UCI research papers at the most appropriate 


\begin{tabular}{|c|c|c|c|}
\hline Academic journal & Author (year) & $\begin{array}{l}\text { User-centric innovation } \\
\text { category }\end{array}$ & Empirical study \\
\hline Advances in Consumer Research & Füller (Füller, 2006) & User Motivations & Quantitative \\
\hline California Management Review & Füller (2010) & User Motivations / Characteristics & Mixed Method \\
\hline Creativity and Innovation Management & Bullinger et al. (2010) & User Communities & Mixed Method \\
\hline IEEE Transactions on Engineering Management & Lettl et al. (2008) & User Characteristics & Mixed Method \\
\hline Industry and Innovation & Kaiser and Müller-Seitz (2008) & User Motivations & Mixed Method \\
\hline Information, Communication \& Society & Brabham (2010) & User Motivations & Qualitative \\
\hline International Journal of Electronic Commerce & Jang et al. (2008) & User Communities & Quantitative \\
\hline International Journal of Technology Management & Lettl et al. (2006) & User Characteristics & Qualitative \\
\hline Journal of Business and Industrial Marketing & Lettl and Gemunden (2005) & User Motivations & Mixed Method \\
\hline Journal of Business Research & Füller et al. (2007) & User Communities & Secondary Data \\
\hline Journal of Macromarketing & Bonsu and Darmody (2008) & User Benefits & Qualitative \\
\hline Journal of Management Information Systems & Füller et al. (2009) & User Benefits & Quantitative \\
\hline Journal of Marketing & Algesheimer et al. (2005) & User Communities & Quantitative \\
\hline Journal of Marketing Communications & Casaló et al. (2008) & User Communities / Motivations & Quantitative \\
\hline
\end{tabular}


Journal of Product Innovation Management

Management Science

MIT Sloan Management Review

Organization Science

R\&D Management

Research Policy
Füller et al. (2008)

Schreier and Prugl (2008)

Bagozzi and Dholakia (2006a)

Antorini et al. (2012)

Jeppesen and Frederiksen (2006)

Hienerth (2006)

Corrocher and Zirulia (2010)

de Jong and von Hippel (2009)

Lüthje et al. (2005)

Oliveira and von Hippel (2011)
User Motivations

User Characteristics

User Communities

User Communities

User Characteristics

User Communities

User Characteristics

User Motivations

User Motivations

User Characteristics
Quantitative

Quantitative

Mixed Method

Qualitative

Mixed Method

Qualitative

Secondary Data

Quantitative

Quantitative

Secondary Data 
journals. In conclusion, the need for more primary and qualitative research into UCI is attested throughout the literature review that highlights how many of the UCI empirical studies to date have been derived from either secondary data, quantitative studies and/or mixed method studies. These studies are perhaps not sufficiently targeted and in-depth to successfully drive forward our understanding of this exploratory research topic.

The third objective was to critically analyse the discussion on each of the UCI topics. This was conducted throughout the paper in each section that corresponded to the identified perspectives and themes from the SLR protocol. The key findings from the empirical studies were critically reviewed in the context of the identified research gaps and empirical studies and a summary of these findings is presented in Table 5. The discussion highlighted many weaknesses and lacks of cohesion in the reviewed literature. For instance, there were many cases of papers not citing previous seminal works in their research area (Corrocher and Zirulia, 2010; Criscuolo et al., 2012; Di Gangi and Wasko, 2009; Hienerth and Lettl, 2011; Laursen, 2011), calling for research into areas of UCI that have recently been empirically investigated (Ebner et al., 2009; Ebner et al., 2009; Füller et al., 2007) or making strong arguments on UCI matters in papers not specifically addressing UCI research or based on secondary data (Laursen and Salter, 2006). There were also cases of authors overlooking valid calls for research in favour of conducting more niche studies that do not advance our understanding of UCI as a whole (Berthon et al., 2008; Burger-Helmchen and Guittard, 2008; Cova and Pace, 2006; Franke et al., 2006; Sawhney et al., 2005; Simula and Vuori, 2012). The authors have therefore concluded that the contemporary UCI literature since 2005 has suffered from substantial fragmentation and a deficiency of clarity and structure regarding what areas have been analysed empirically or neglected, what the key findings have been and what are our current understandings of UCI in the digital age. 
Despite the above identified weaknesses in the literature, this research paper has taken initial steps towards disentangling the literature and providing a clear and robust overview of the literature on account of the SLR that was conducted. The current paper also attempted to facilitate clarification through the provision of detailed accounts of the research gaps in Table 2, the empirical studies in Table 3 and the subsequent critical discussion on a range of important UCI topics. The research framework in Table 5 has endeavoured to provide a clear and well-structured framework of what our understandings of UCI are and where future research needs to be focussed.

The final objective of this paper was to demonstrate how the findings from the current research into consumer-related UCI topics have implications for practitioners. This objective has been considered when discussing the findings of the UCI literature that was reviewed throughout the paper, and a number of key insights can now be drawn. In terms of the role of user perspectives on practitioner implications, management should consider the complexities of user characteristics and their associated motivations to participate in user innovations. A more systematic approach will help to successfully develop user toolkits and communities into innovation strategies that are mutually beneficial and overcome the challenges associated with transferring innovation between users and producers within UCI (Baldwin et al., 2006; Di Gangi and Wasko, 2009; Henkel and von Hippel, 2005). Many of these challenges are associated with a lack of user understanding and knowledge of the technological aspect of UCI; therefore practitioners who provide a guided approach to informing users of the technology via the implementation of toolkits or community activities may incur resulting user contributions that are more practicable - yet less original (Magnusson, 2009). Other challenges for the consumers relate to their potentially negative perceptions of how they can benefit from engaging in UCI activities; therefore, firm management should prioritise the 
clarification and emphasis of the positive ramifications for the users - including the advocating of low expenditure level perceptions (Piller et al., 2005).

Our summary findings from the SLR that are presented in Table 5 show that user communities in particular should be carefully evaluated by firm management as they can represent both significant risks in relation to resource requirements (Dahlander and Wallin 2006) and stakeholder conflict (Di Gangi and Wasko 2009), as well as opportunities for capitalising on NPD by identifying the strengths and weaknesses of new products/services whilst cultivating brand loyalty (Kim et al. 2008). Through increased commitment to user community development, practitioners may derive enhanced financial performance as a result of word-of-mouth marketing and customer rephrasing (Jang et al., 2008). It may also be advisable for firms to initiate both communication and group unanimity within user communities in order to facilitate and develop member interactions; this may assist in establishing long-term sustainability for the community and ultimately brand commitment from the users (Casaló et al., 2008).

For practitioners who seek to instigate communication and group unity with user communities through the organisation of innovation contests, their successful and proactive assimilation through community boundaries may depend on designing contests that represent individual drivers. Furthermore, contest design should also permit and encourage submissions from users that exhibit elevated levels of competitive orientation in order to maximise the innovativeness of the submissions (Bullinger et al., 2010). Once these innovative lead users are identified within the communities through these organised contests or otherwise, firm management may benefit from implementing relevant strategies to incorporate involvement from these users at various NPD stages as well as developing long-term relationships (Kim et $a l ., 2008)$. This is especially appropriate where the community lead users are employed by similar or related firms as the integration of these users into the development team of the host 
firm can facilitate mutually beneficial partnerships with the external stakeholder firm (Antorini et al., 2012). Moreover, practitioners should also seriously consider the risk factors implicit in community disruption as the lack of control from the host firm over the content can potentially result in conflict or complaints; this is increasingly probable as the community becomes more closely integrated with the activities and product/service of the host firm (Di Gangi and Wasko, 2009).

By carefully considering the characteristics and motivations of consumers as detailed in our summary findings in Table 5, practitioners may enhance their abilities to develop greater UCI strategies to appeal to the consumers' specific requirements. For instance, by ascertaining which product-related resources the consumers are lacking, it will not only provide organisations with details of the consumers' ahead-of-the-market needs but may also be used to devise effective recognition-based proactive UCI strategies. An alternative strategy for firm management would be to analyse the positive traits of creative users in order to ascertain future creative users and augment the creative capacity of the practitioner through the incorporation of radically new creative solutions (Alam, 2006). The characteristics of personal user needs may represent a hobbyist status for the consumers, and by ascertaining the type and details of these individual needs, organisations can develop greater understanding of consumers' proactivity traits that can lead to more efficient reactive UCI strategies. Furthermore, as lead user involvement is of particular interest to practitioners due to their eclectic range of contributions and knowledge, they could capitalise on these attributes by devising and implementing innovative ways to facilitate interaction and integration with these lead users (Lettl et al., 2008). As the key practitioner challenge here may lie in the identification of these lead users, it may be advisable for them consider both field-dependent and field-independent variables to narrow the search field and improve the detection process (Schreier and Prugl, 2008). A summary of the above practitioner 
implications are presented in Figure 1 below, which illustrates the various user-related UCI topics, the proposed approaches by practitioners to each topics, and the implications (both positive and negative) of implementing these approaches.

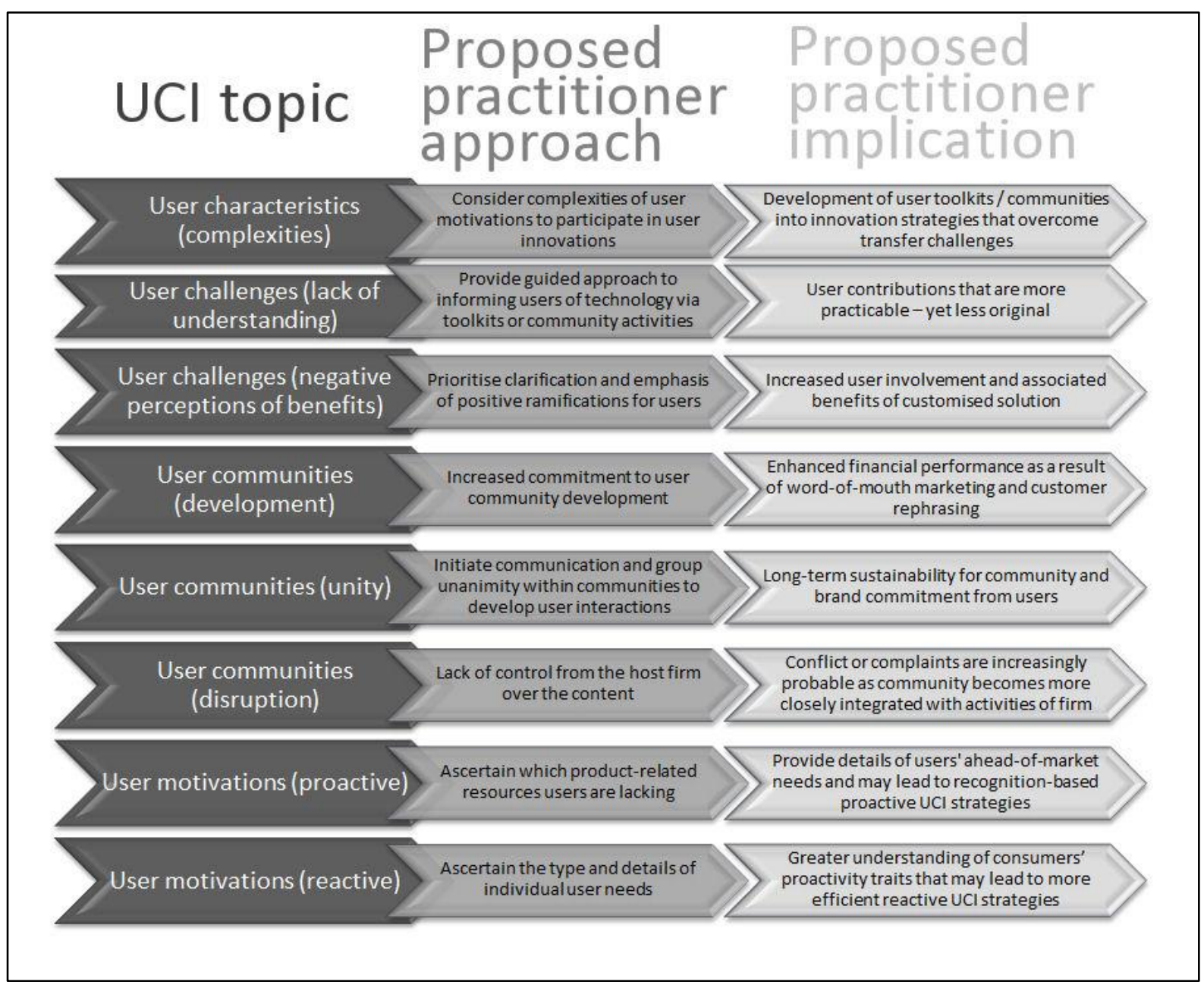

Figure 1. $\quad$ Proposed practitioner approaches and implications of UCI topics

\section{Research implications}

Overall, this SLR on UCI, and our summary findings in Table 5 in particular, have shown that the current state of the literature on UCI is not only fragmented in terms of an understanding of various UCI topics, but is also unbalanced in terms of which UCI topics require greater research focus compared to the current saturation of similar or unnecessary empirical studies. Furthermore, this further research may also facilitate stronger research and marketing abilities by gaining a greater understanding of identifying user-innovators and how 
they can be managed (Lettl et al., 2006; Lüthje and Herstatt, 2004). This clarification may in turn enhance the firm's understanding of the external innovation activities going on within user communities and learning how to influence them, establishing more efficient risk assessment strategies for managing the benefits and issues regarding future UCI (Harhoff $e t$ al., 2003; Henkel and von Hippel, 2005). This may ultimately lead to superior overall business operations regarding critical factors such as strategic management and resource allocation (Hienerth and Lettl, 2011; Piller and Walcher, 2006; Shah and Tripsas, 2007).

In terms of a specific agenda for future UCI research, Table 5 provides directions for future empirical study to address gaps in relation to the discussed UCI topics of user benefits, communities, challenges, motivations and characteristics. A total of twenty unanswered research gaps remain and Table 5 clearly shows how the topic of user challenges is associated with more unanswered research questions than the other topics. Therefore, future empirical UCI research could focus on this topic and address one or more of the five associated research gaps. These gaps relate to perceptions of consumers as organisational 'labourers' (Brabham, 2008); consumer perceptions of distributed or co-located settings during the process of UCI (Enkel et al., 2005); quantitatively studying the proficiency levels for consumer participation in radical innovations (Lettle, 2007); optimal knowledge levels for guaranteeing technical feasibility (Magnusson, 2009) and user opposition to company attempts to manipulate their UCI involvement (Brabham, 2008). Ultimately, however, any of the twenty identified unanswered research gaps would represent adequate starting points for a UCI empirical research agenda because they have been substantiated as a result of the SLR protocol that was implemented for this literature review paper. Finally, the list of originating journals of empirical UCI studies presented in Table 6 may prove an instrumental aspect of this research agenda as UCI researchers can observe at a glance the academic journals that have recently published empirical papers in the specific area of their intended UCI topic. 


\section{Limitations}

This research paper was subject to a number of limitations that we acknowledge. UCI is positioned within the broader management topic of open innovation that has been discussed extensively throughout the literature and was therefore not examined in detail in this paper. The authors concede that our understanding of UCI raises a number of questions regarding the individual interactions and the domain of the research. Due to resource limitations, we were unable to compare these individual interactions in terms of which are most representative of the UCI concept and were unable to address the prospect of UCI with B2B buyers instead of end consumers. These are valid discussion topics that could be addressed by future research studies into UCI. The decision to limit the literature reviews to only academic journal articles published from 2005-13 was taken primarily on account of the research objectives that related to our contemporary understanding of the topic; however the decision was also taken due to resource limitations as an extensive longitudinal study of UCI would have far exceeded our abilities to adequately discuss the literature and present our findings in a meaningful manner. Regarding the SLR methodology used, the importance of a structured and multiple-stage system for reviewing a large volume of academic literature has been discussed extensively in other key management research papers (see Pittaway et al., 2004; Pittaway and Cope, 2007; Thorpe et al., 2006) and was therefore not reviewed further in the current paper.

\section{References}

Agerfalk, P.J. and Fitzgerald, B. (2008) Outsourcing to an unknown workforce: Exploring opensourcing as a global sourcing strategy. MIS quarterly 32 (2) pp 385-409

Alam, I. (2006) Removing the fuzziness from the fuzzy front-end of service innovations through customer interactions. Industrial Marketing Management 35 (4) pp 468-480 
Algesheimer, R., Dholakia, U.M. and Herrmann, A. (2005) The social influence of brand community: Evidence from european car clubs. Journal of Marketing 69 (3) pp 19-34

Bagozzi, R.P. and Dholakia, U.M. (2006a) Antecedents and purchase consequences of customer participation in small group brand communities. International Journal of Research in Marketing 23 (1) pp 45-61

Bagozzi, R.P. and Dholakia, U.M. (2006b) Open source software user communities: A study of participation in linux user groups. Management science 52 (7) pp 1099-1115

Baldwin, C., Hienerth, C. and von Hippel, E. (2006) How user innovations become commercial products: A theoretical investigation and case study. Research Policy 35 (9) pp $1291-1313$

Berthon, P., Pitt, L. and Campbell, C. (2008) Ad lib: When customers create the ad. California Management Review 50 (4) pp 129-159

Berthon, P., Pitt, L.F., McCarthy, I. and Kates, S.M. (2007) When customers get clever: Managerial approaches to dealing with creative consumers. Business horizons 50 (1) pp 3947

Blazevic, V. and Lievens, A. (2008) Managing innovation through customer coproduced knowledge in electronic services: An exploratory study. Journal of the Academy of Marketing Science 36 (1) pp 138-151

Bogers, M., Afuah, A. and Bastian, B. (2010) Users as innovators: A review, critique, and future research directions. Journal of Management 36 (4) pp 857-875

Bonsu, S.K. and Darmody, A. (2008) Co-creating second life Market-Consumer cooperation in contemporary economy. Journal of Macromarketing 28 (4) pp 355-368

Brabham, D.C. (2008) Crowdsourcing as a model for problem solving an introduction and cases. Convergence: the international journal of research into new media technologies 14 (1) pp 75-90

Brabham, D.C. (2010) Moving the crowd at threadless: Motivations for participation in a crowdsourcing application. Information, Communication \& Society 13 (8) pp 1122-1145

Braun, V. and Herstatt, C. (2007) Barriers to user innovation: Moving towards a paradigm of 'licence to innovate'? International Journal of Technology, Policy and Management 7 (3) pp 292-303

Bullinger, A.C., Neyer, A., Rass, M. and Moeslein, K.M. (2010) Community-based innovation contests: Where competition meets cooperation. Creativity and innovation management 19 (3) pp 290-303

Burger-Helmchen, T. and Guittard, C. (2008) Are users the next entrepreneurs? A case study on the video game industry. International Journal of Entrepreneurship Education 6 (1) pp 5774 
Carson, D., Gilmore, A., Perry, C. and Gronhaug, K. (2001) Qualitative marketing research.London: Sage Publications Ltd.

Casaló, L.V., Flavián, C. and Guinalíu, M. (2008) Promoting consumer's participation in virtual brand communities: A new paradigm in branding strategy. Journal of Marketing Communications 14 (1) pp 19-36

Corrocher, N. and Zirulia, L. (2010) Demand and innovation in services: The case of mobile communications. Research Policy 39 (7) pp 945-955

Cova, B. and Pace, S. (2006) Brand community of convenience products: New forms of customer empowerment-the case "my nutella the community". European Journal of Marketing 40 (9/10) pp 1087-1105

Criscuolo, P., Nicolaou, N. and Salter, A. (2012) The elixir (or burden) of youth? exploring differences in innovation between start-ups and established firms. Research Policy 41 (2) pp 319-333

Dahlander, L. and Wallin, M.W. (2006) A man on the inside: Unlocking communities as complementary assets. Research Policy 35 (8) pp 1243-1259

de Jong, J. and von Hippel, E. (2009) Transfers of user process innovations to process equipment producers: A study of dutch high-tech firms. Research Policy 38 (7) pp 1181-1191

Desouza, K.C., Awazu, Y., Jha, S., Dombrowski, C., Papagari, S., Baloh, P. and Kim, J.Y. (2008) Customer-driven innovation. Research Technology Management 51 (3) pp 35-44

Di Gangi, P.M. and Wasko, M. (2009) Steal my idea! organizational adoption of user innovations from a user innovation community: A case study of dell IdeaStorm. Decision Support Systems 48 (1) pp 303-312

Ebbesson, E. (2012) Facilitating distributed multi-stakeholder co-creative innovation processes-a case from the media industry. In: Information Systems Research Seminar in Scandinavia. 17 - 20th August 2012 Sigtuna, Sweden. Tapir Akademisk Forlag, 69-82.

Ebner, W., Leimeister, J.M. and Krcmar, H. (2009) Community engineering for innovations: The ideas competition as a method to nurture a virtual community for innovations. $\underline{R} \& \mathrm{~d}$ Management 39 (4) pp 342-356

Enkel, E., Kausch, C. and Gassmann, O. (2005) Managing the risk of customer integration. European Management Journal 23 (2) pp 203-213

Etgar, M. (2008) A descriptive model of the consumer co-production process. Journal of the Academy of Marketing Science 36 (1) pp 97-108

Faulkner, P. and Runde, J. (2009) On the identity of technological objects and user innovations in function. Academy of Management Review 34 (3) pp 442-462 
Franke, N., von Hippel, E. and Schreier, M. (2006) Finding commercially attractive user innovations: An exploration and test of "lead user" theory. Journal of Product Innovation Management 23 (4) pp 301-315

Füller, J., Jawecki, G. and Muhlbacher, H. (2007) Innovation creation by online basketball communities. Journal of Business Research 60 (1) pp 60-71

Füller, J. (2006) Why consumers engage in virtual new product developments initiated by producers. Advances in Consumer Research 33 (1) pp 639-646

Füller, J. (2010) Refining virtual co-creation from a consumer perspective. California management review 52 (2) pp 98-122

Füller, J., Matzler, K. and Hoppe, M. (2008) Brand community members as a source of innovation. Journal of Product Innovation Management 25 (6) pp 608-619

Füller, J., Mühlbacher, H., Matzler, K. and Jawecki, G. (2009) Consumer empowerment through internet-based co-creation. Journal of Management Information Systems 26 (3) pp 71-102

Gamble, J.R. and Gilmore, A. (2013) A new era of consumer marketing? an application of co-creational marketing in the music industry. European Journal of Marketing 47 (11/12) pp TBA

Greer, C.R. and Lei, D. (2012) Collaborative innovation with customers: A review of the literature and suggestions for future research. International Journal of Management Reviews 14 (1) pp 63-84

Harhoff, D., Henkel, J. and von Hippel, E. (2003) Profiting from voluntary information spillovers: How users benefit by freely revealing their innovations. Research Policy 32 (10) pp 1753-1769

Harrison, T., Waite, K. and Hunter, G.L. (2006) The internet, information and empowerment. European Journal of Marketing 40 (9/10) pp 972-993

Henkel, J. and von Hippel, E. (2005) Welfare implications of user innovation. Journal of Technology Transfer 30 (1-2) pp 73-87

Hienerth, C. (2006) The commercialization of user innovations: The development of the rodeo kayak industry. R\&D Management 36 (3) pp 273-294

Hienerth, C. and Lettl, C. (2011) Exploring how peer communities enable lead user innovations to become standard equipment in the industry: Community pull effects. Journal of Product Innovation Management 28 (s1) pp 175-195

Howe, J. (2009) Crowdsourcing: Why the power of the crowd is driving the future of business.New York : Random House. 
Jang, H., Olfman, L., Ko, I., Koh, J. and Kim, K. (2008) The influence of on-line brand community characteristics on community commitment and brand loyalty. International Journal of Electronic Commerce 12 (3) pp 57-80

Janssen, K.L. and Dankbaar, B. (2008) Proactive involvement of consumers in innovation: Selecting appropriate techniques. International Journal of Innovation Management 12 (03) pp 511-541

Jeppesen, L.B. and Molin, M.J. (2003) Consumers as co-developers: Learning and innovation outside the firm. Technology Analysis \& Strategic Management 15 (3) pp 363-383

Jeppesen, L.B. and Frederiksen, L. (2006) Why do users contribute to firm-hosted user communities? the case of computer-controlled music instruments. Organization Science 17 (1) pp 45-63

Jespersen, K.R. and Buck, N. (2010) Usage of ICT tools in new product development: creating user-involvement. In: Al-Hakim, L. and Jin, C. eds. Innovation in Business and 30 Enterprise: Technologies and Frameworks. New York : Business Science Reference, 76-90.

Kaiser, S. and Müller-Seitz, G. (2008) Leveraging lead user knowledge in software development - the case of weblog technology. Industry and Innovation 15 (2) pp 199-221

Kim, J.H., Bae, Z. and Kang, S.H. (2008) The role of online brand community in new product development: Case studies on digital product manufacturers in korea. International Journal of Innovation Management 12 (3) pp 357-376

Kleemann, F., Voß, G.G. and Rieder, K. (2008) Un (der) paid innovators: The commercial utiliza-tion of consumer work through crowdsourcing. Science, Technology \& Innovation Studies 4 (1) pp PP. 5-26

Kristensson, P., Matthing, J. and Johansson, N. (2008) Key strategies for the successful involvement of customers in the co-creation of new technology-based services. International Journal of Service Industry Management 19 (4) pp 474-491

Laursen, K. (2011) User-producer interaction as a driver of innovation: Costs and advantages in an open innovation model. Science and Public Policy 38 (9) pp 713-723

Laursen, K. and Salter, A. (2006) Open for innovation: The role of openness in explaining innovation performance among U.K. manufacturing firms. Strategic Management Journal 27 (2) pp 131-150

Lettl, C. (2007) User involvement competence for radical innovation. Journal of Engineering and Technology Management 24 (1) pp 53-75

Lettl, C. and Gemünden, H.G. (2005) The entrepreneurial role of innovative users. Journal of Business \& Industrial Marketing 20 (7) pp 339-346

Lettl, C., Herstatt, C. and Gemuenden, H.G. (2006) Learning from users for radical innovation. International Journal of Technology Management 33 (1) pp 25-45 
Lettl, C., Hienerth, C. and Gemuenden, H.G. (2008) Exploring how lead users develop radical innovation: Opportunity recognition and exploitation in the field of medical equipment technology. IEEE Transactions on Engineering Management 55 (2) pp 219-233

Lettl, C., Herstatt, C. and Gemuenden, H.G. (2006) Users' contributions to radical innovation: Evidence from four cases in the field of medical equipment technology. R\&D Management 36 (3) pp 251-272

Lüthje, C. (2004) Characteristics of innovating users in a consumer goods field: An empirical study of sport-related product consumers. Technovation 24 (9) pp 683-695

Lüthje, C. and Herstatt, C. (2004) The lead user method: An outline of empirical findings and issues for future research. R\&D Management 34 (5) pp 553-568

Lüthje, C., Herstatt, C. and von Hippel, E. (2005) Userinnovators and "local" information: The case of mountain biking. Research Policy 24 (6) pp 951-965

Magnusson, P.R. (2009) Exploring the contributions of involving ordinary users in ideation of technology-based services. Journal of Product Innovation Management 26 (5) pp 578-593

Min Antorini, Y., Muniz, J.,Albert M. and Askildsen, T. (2012) Collaborating with customer communities: Lessons from the lego group. MIT Sloan Management Review 53 (3) pp 73-79

Morrison, P.D., Roberts, J.H. and von Hippel, E. (2000) Determinants of user innovation and innovation sharing in a local market. Management Science 46 (12) pp 1513-1527

Nambisan, S. and Baron, R.A. (2007) Interactions in virtual customer environments: Implications for product support and customer relationship management. Journal of Interactive Marketing 21 (2) pp 42-62

Neuman, W.L. (1994) Social Research Methods: Qualitative and Quantitative Approaches.Boston : Allyn and Bacon.

Oliveira, P. and von Hippel, E. (2011) Users as service innovators: The case of banking services. Research Policy 40 (6) pp 806-818

Payne, A., Storbacka, K., Frow, P. and Knox, S. (2009) Co-creating brands: Diagnosing and designing the relationship experience. Journal of Business Research 62 (3) pp 379-389

Piller, F.T. and Walcher, D. (2006) Toolkits for idea competitions: A novel method to integrate users in new product development. R\&D Management 36 (3) pp 307-318

Piller, F., Ihl, C. and Vossen, A. (2010) A typology of customer co-creation in the innovation process. Available at SSRN 1732127 (working paper) pp 1-26

Piller, F., Schubert, P., Koch, M. and Möslein, K. (2005) Overcoming mass confusion: Collaborative customer co-design in online communities. Journal of Computer-Mediated Communication 10 (4) pp 1-28 
Pittaway, L. and Cope, J. (2007) Entrepreneurship education: A systematic review of the evidence. International Small Business Journal 25 (5) pp 479-510

Pittaway, L., Robertson, M., Munir, K., Denyer, D. and Neely, A. (2004) Networking and innovation: A systematic review of the evidence. International Journal of Management

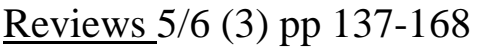

Rowley, J., Kupiec-Teahan, B. and Leeming, E. (2007) Customer community and cocreation: A case study. Marketing Intelligence \& Planning 25 (2) pp 136-146

Sawhney, M., Verona, G. and Prandelli, E. (2005) Collaborating to create: The internet as a platform for customer engagement in product innovation. Journal of Interactive Marketing 19 (4) pp 4-17

Schreier, M. and Prügl, R. (2008) Extending lead-user theory: Antecedents and consequences of consumers' lead userness. Journal of Product Innovation Management 25 (4) pp 331-346

Shah, S.K. and Tripsas, M. (2007) The accidental entrepreneur: The emergent and collective process of user entrepreneurship. Strategic Entrepreneurship Journal 1 (1) pp 123-140

Simula, H. and Vuori, M. (2012) Benefits and barriers of crowdsourcing in B2B firms: Generating ideas with internal and external crowds. International Journal of Innovation Management 16 (6) pp 1-19

Thorpe, R., Holt, R., Macpherson, A. and Pittaway, L. (2006) Using knowledge within small and medium-sized firms: A systematic review of the evidence. International Journal of Management Reviews 7 (4) pp 257-281

Tietz, R., Morrison, P.D., Lüthje, C. and Herstatt, C. (2005) The process of user-innovation: A case study in a consumer goods setting. International Journal of Product Development 2 (4) pp 321-338

Tranfield, D., Denyer, D. and Smart, P. (2003) Towards a methodology for developing evidence-informed management knowledge by means of systematic review. British Journal of Management 14 (3) pp 207-222

von Hippel, E. (2001) Innovation by user communities: Learning from open-source software. Sloan Management Review 42 (4) pp 82-86

von Hippel, E. (2007) Horizontal innovation networks: By and for users. Industrial and Corporate Change 16 pp 293-315

Wright, C., Sturdy, A. and Wylie, N. (2012) Management innovation through standardization: Consultants as standardizers of organizational practice. Research Policy 41 (3) $\mathrm{pp} 652-662$

Zwick, D., Bonsu, S.K. and Darmody, A. (2008) Putting consumers to work: Co-creationand new marketing govern-mentality. Journal of Consumer Culture 8 (2) pp 163-196 